\title{
Turbulence in an inundated urban environment during a major flood: implications in terms of people evacuation and sediment deposition
}

\author{
H. Chanson ${ }^{1, a}$ And R. Brown ${ }^{2}$ \\ 1 The University of Queensland, School of Civil Engineering, Brisbane Q4072, Australia \\ 2 Queensland University of Technology, Science and Engineering Faculty, Brisbane Q4000, Australia
}

Received 17 June 2013, Accepted 10 March 2014

\begin{abstract}
Floods through inundated urban environments constitute a hazard to the population and infrastructure. A series of field measurements were performed in an inundated section of the City of Brisbane (Australia) during a major flood in January 2011. Using an acoustic Doppler velocimeter (ADV), detailed velocity and suspended sediment concentration measurements were conducted about the peak of the flood. The results are discussed with a focus on the safety of individuals in floodwaters and the sediment deposition during the flood recession. The force of the floodwaters in Gardens Point Road was deemed unsafe for individual evacuation. A comparison with past laboratory results suggested that previous recommendations could be inappropriate and unsafe in real flood flows.
\end{abstract}

Key words: Flooding / urban environment / field data / turbulence / evacuation safety / sediment

\section{Introduction}

The flooding of urbanised areas constitutes a hazard to the population and infrastructure. Some recent catastrophes included the inundations of Vaison-la-Romaine (France) in 1992, Nîmes (France) in 1998, New Orleans (USA) in 2005, Rockhampton, Bundaberg, and Brisbane during the 2010-2011 summer in Queensland (Australia). Floods through inundated urban environments have been studied only recently. Some studies looked into the flow patterns and redistribution in streets during storm events and the implication in terms of flood modelling $[1,2]$. A number of studies investigated the impact of floods on structures and buildings [3]. A few considered the potential impact of flowing waters on pedestrians [4-6]. Despite some near-full-scale physical tests, no study to date considered the level of flow turbulence and its impact on evacuation safety.

Herein a series of field measurements were performed in an inundated section of the City of Brisbane (Australia) in January 2011. Using an acoustic Doppler velocimeter (ADV), detailed velocity and suspended sediment concentration measurements were conducted about the peak of the flood. The results are detailed and presented, with a focus on the safety of individuals in floodwaters and the sediment deposition during the flood recession.

\footnotetext{
a Corresponding author: h.chanson@uq.edu.au
}

\section{Hydrology, sampling site and instrumentation}

Between November 2010 and January 2011, some major rainfalls were recorded across eastern Australia [7]. In January 2011, the City of Brisbane experienced a major flood resulting from a combination of a heavily soaked catchment, some heavy continuous rainfalls during the first fortnight in the whole Brisbane River catchment, and some intense rainstorm events over the upper and middle catchments on 10 and 11 January 2011. All these induced some major flooding in Brisbane with the flood waters peaking on 12 January afternoon and 13 January early morning.

The Central Business District (CBD) of the City of Brisbane is located 22 to $24 \mathrm{~km}$ upstream of the river mouth within the estuarine zone and the catchment area is $13500 \mathrm{~km}^{2}$. Figure 1 presents an aerial view of the 2011 field site location (red arrow) and city centre. On 12 to 14 January 2011, an acoustic Doppler velocimeter SonTek ${ }^{\mathrm{TM}}$ microADV was deployed in the inundated Gardens Point Road (Fig. 2). The ADV unit was sampled at $50 \mathrm{~Hz}$ continuously for 5 periods ranging from 10 to $266 \mathrm{~min}$; the study did not yield a continuous data set because of a number of practical issues experienced during the investigation [8]. Figure 2 shows the site during the flood: the water depth ranged between about $1 \mathrm{~m}$ and zero 


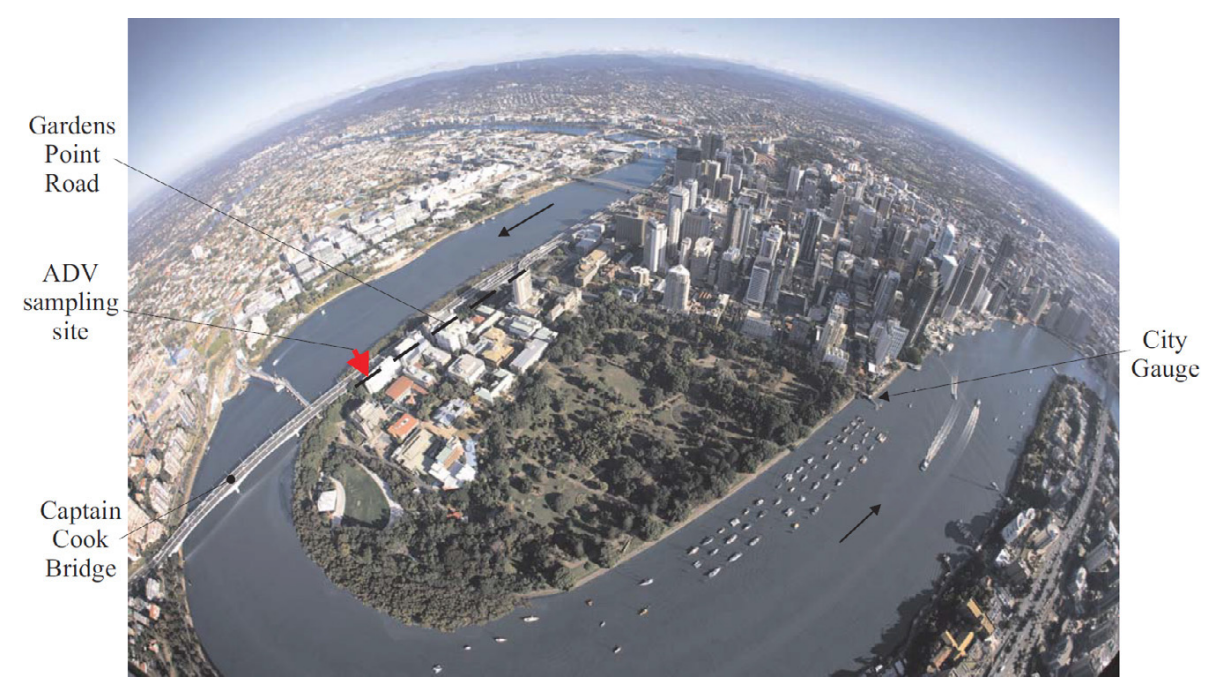

Fig. 1. City of Brisbane and Brisbane River during a dry season (Courtesy of Brisbane Marketing) - The black arrows show the main river flow direction, the thick dashed line corresponds to Gardens Point Road and the red arrow points to the sampling site.

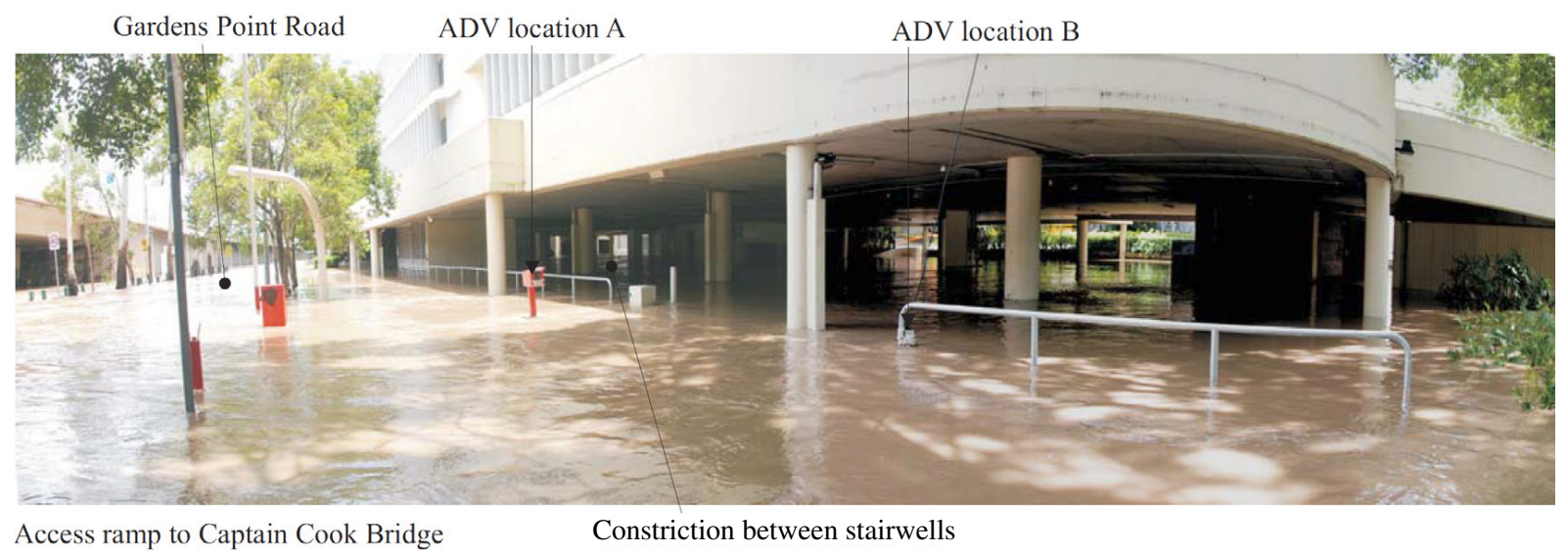

Fig. 2. Gardens Point Road on 13 January 2011 morning - Looking upstream with the ADV sampling at location B.

when the flood receded. This site was located between a busy access ramp and a car park building (C Block) during normal weather conditions; it was not a permanent monitoring site. For the first two periods, the ADV was mounted at location $\mathrm{A}$; it was relocated to location $\mathrm{B}$ on 13 January 2011. All the ADV data underwent a thorough post-processing which included the removal of communication errors, the removal of average correlation values less than $60 \%$ and the removal of average signal to noise ratio (SNR) data less than $5 \mathrm{~dB}[8]$.

Some sediment material was collected next to the sampling site about the high water line on 13 and 14 January 2011. The median particle size was in the silt size range with an approximate diameter of $25 \mu \mathrm{m}$ and a sorting coefficient ranging from 4.6 to 6.6 . The relationship between acoustic backscatter amplitude (Ampl) of the ADV unit and suspended sediment concentrations (SSC) was tested in laboratory for SSCs between 0 and $98 \mathrm{~kg} \cdot \mathrm{m}^{-3}$, allowing to estimate the instantaneous suspended sediment concentration from the instantaneous signal amplitude during the field study [9].

\section{Basic observations}

The ADV unit was used at two locations (Fig. 2) where the ADV sampling volume was at 0.35 and $0.083 \mathrm{~m}$ above the bed. Figure 3 shows the time variations of longitudinal velocity and the data are compared with the water elevations measured at the sampling site and water elevations of the Brisbane River at the City Gauge located $1.55 \mathrm{~km}$ downstream. In Figure 3, the bed elevation (3.42 $\mathrm{m} \mathrm{AHD)}$ at the sampling site is included with a thick dashed line using the same vertical scale as the City Gauge water elevation data. The longitudinal velocity data highlighted some very large fluctuations around a mean trend (thick black line, Fig. 3) during the study. The mean velocity was about $0.5 \mathrm{~m} . \mathrm{s}^{-1}$, but during the last data period $\mathrm{T} 5$ when the mean velocity was less than $0.005 \mathrm{~m} . \mathrm{s}^{-1}$ (see Sect. 4.1). For comparison, the longitudinal velocity in the main river channel was probably between 3.5 and $4.5 \mathrm{~m} . \mathrm{s}^{-1}$.

During the whole study, the large fluctuations of all velocity components were caused largely by slow oscillations 
Time (hours) since 00:00 on 12/01/2011

$\begin{array}{lllllllllllllllll}19.5 & 21 & 22.5 & 24 & 25.5 & 27 & 28.5 & 30 & 31.5 & 33 & 34.5 & 36 & 37.5 & 39 & 40.5 & 42 & 43.5\end{array}$

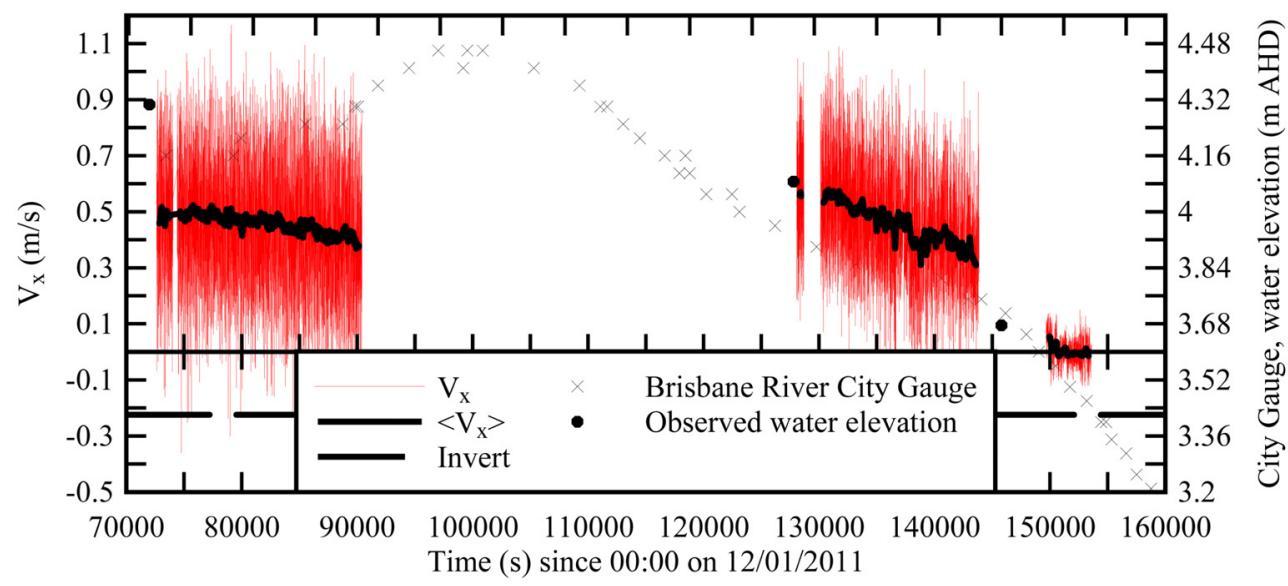

Fig. 3. Time variations of the instantaneous and mean longitudinal velocity component at Gardens Point Road during on 12-14 January 2011 - Comparison with the Brisbane River City Gauge data (black cross) and water elevation observations on site The thick dashed line indicates the bed elevation at the sampling site.

Time (h) since 00:00 on 12/01/2011

$\begin{array}{lllllllllllllllll}19.5 & 21 & 22.5 & 24 & 25.5 & 27 & 28.5 & 30 & 31.5 & 33 & 34.5 & 36 & 37.5 & 39 & 40.5 & 42 & 43.5\end{array}$

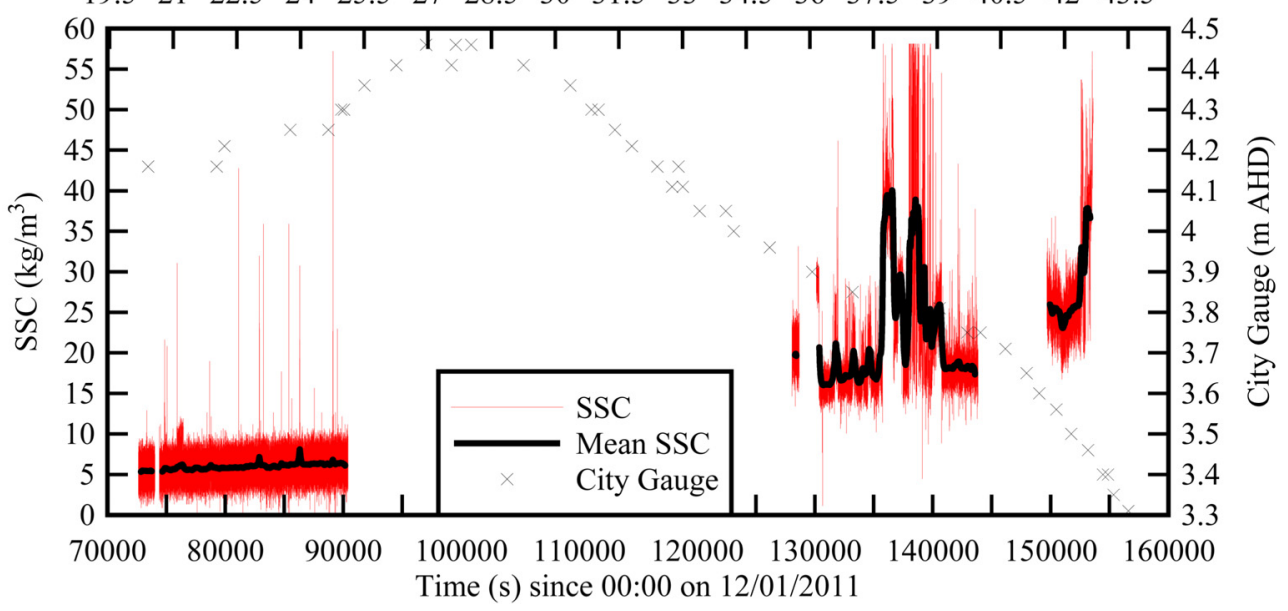

Fig. 4. Time variations of the instantaneous and mean suspended sediment concentration (SSC) at Gardens Point Road during on 12-14 January 2011 - Comparison with the Brisbane River City Gauge data.

with dominant periods of about 60 to $100 \mathrm{~s}$, which were felt when the authors were in the waters. It was suggested that the flow constriction created by the concrete stairwells seen in Figure 2 induced some choking; the gap between stairwells was significantly smaller than the car park width; when the flow in the stairwell contraction choked, the energy losses in the contraction became substantially larger than the rate of energy loss of the main flow, and the inundation flow would redirect around the stairwells to achieve a minimum energy path. The flow pattern yielded some flow instabilities in the surroundings of stairwells which were amplified when their period was close to the natural sloshing period of the building car park [8].

The time-variations of suspended sediment concentration (SSC) are presented in Figure 4. The SSC data tended to show an increase in mean concentration during the study, from about $6 \mathrm{~kg} \cdot \mathrm{m}^{-3}$ to more than $20 \mathrm{~kg} \cdot \mathrm{m}^{-3}$ (Fig. 4). The SSC data showed some large and rapid fluctuations about the mean trend, typically with periods less than 3 s. During the data period T4 on Thursday 13 January 2011 afternoon, the suspended sediment concentration estimates highlighted some large suspended sediment concentrations and large fluctuations in SSC (Fig. 4), between $t=135600$ and $140800 \mathrm{~s}$. The causes of these remain unexplained.

\section{Discussion}

\subsection{Sediment deposition}

During the last sampling period (T5), the water level dropped rapidly from $0.26 \mathrm{~m}$ down to less than $0.10 \mathrm{~m}$ 


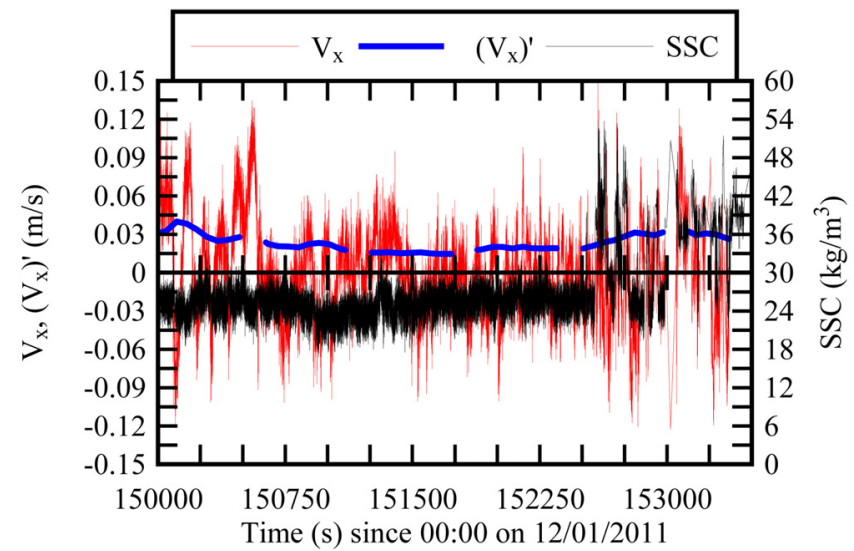

Fig. 5. Time variations of the instantaneous longitudinal velocity component and suspended sediment concentration (SSC), and standard deviation of longitudinal velocity component at Gardens Point Road during on 13-14 January 2011 during the last sampling period T5.

(over $65 \mathrm{~min}$ ) when the ADV unit came to be out of the water. The velocity data showed a very slow motion consistent with the disconnection of the inundated road from the main river channel. The data set corresponded to the final stage of the flood water recession associated with some suspended sediment accretion. The sediment deposits were seen on 14 January 2011 morning when the floodwaters receded: the road and building floors were covered by a 5 to $10 \mathrm{~cm}$ thick mud sludge.

During this last sampling period (T5), the mean velocity magnitude was less than $0.005 \mathrm{~m} . \mathrm{s}^{-1}$ on average, but all three velocity components exhibited large fluctuations. This is illustrated in Figure 5 where the time variations of the longitudinal velocity component are presented. On average, the velocity standard deviation was about $0.03 \mathrm{~m} . \mathrm{s}^{-1}$ : that is, a turbulence intensity $V^{\prime} /|V|$ of about $500 \%$ to $700 \%$. A frequency analysis of the velocity signals showed the existence of slow fluctuations. The dominant periods were about 100 to $105 \mathrm{~s}$ for all three velocity components. The vertical velocity data showed a secondary frequency of about $59 \mathrm{~s}$. The SSC was $28 \mathrm{~kg} . \mathrm{m}^{-3}$ on average during the sampling period T5, with large fluctuations ranging from 17 to $57 \mathrm{~kg} \cdot \mathrm{m}^{-3}$, and a SSC standard deviation of $6.9 \mathrm{~kg} \cdot \mathrm{m}^{-3}$ (Figs. 5 and 6 ). The probability distribution of SSC was bimodal, with a primary mode of $25 \mathrm{~kg} \cdot \mathrm{m}^{-3}$ and a secondary mode about $38 \mathrm{~kg} \cdot \mathrm{m}^{-3}$ (Fig. 6).

\subsection{Individual evacuation safety}

An individual walking in the floodwaters is subjected to a range of forces including its own weight, the buoyancy force, the resultant of pressure forces caused to flow velocity around the individual, and a reaction force. A few studies have looked at the impact of flowing waters on pedestrians and associated hazards $[4,10]$. They suggested two main mechanisms of failure: sliding and tumbling. In
Mean=28.3, Std=6.859, Skewness $=1.703$

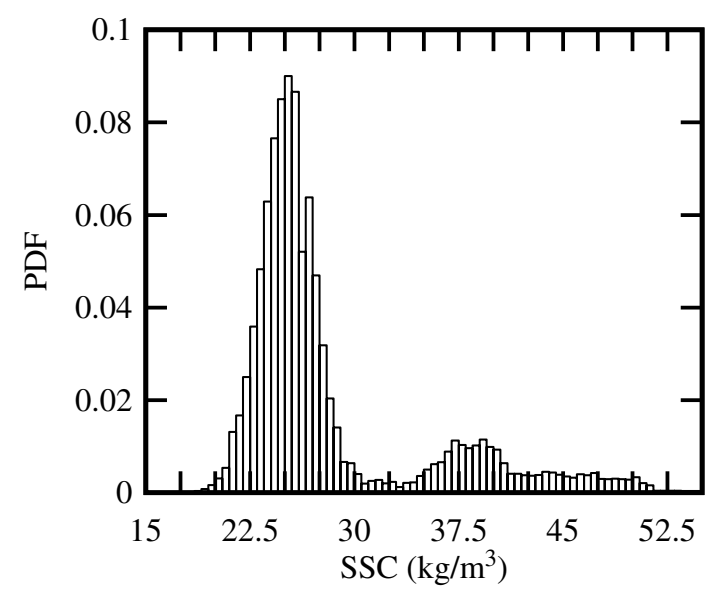

Fig. 6. Normalised probability distribution function of instantaneous suspended sediment concentration (SSC) at Gardens Point Road during on 13-14 January 2011 during the last sampling period T5.

January 2011, the authors experienced first hand the force of the flood flow in Gardens Point Road. They used secured safety ropes and safety handrails to work safely in the flood waters. The authors would not describe the flow conditions as safe for evacuation because of the intense turbulent mixing and the water surges which were felt at irregular intervals.

Although some studies used the flow velocity as a design parameter, the specific force per unit width, or momentum function, is another parameter to plan the safe evacuation of individuals [5]. Herein the momentum function is calculated as: $M=d^{2} / 2+d V_{x}^{2} / 2$, where $d$ and $V_{x}$ are respectively the instantaneous water depth and longitudinal velocity. A constant vertical profile of $V_{x}$ is assumed; this may have limited validity in the present fluctuating flow. Figure 7 presents the time-variations of the instantaneous specific momentum at location A during tests $\mathrm{T} 1$ and $\mathrm{T} 2$ and the probability distribution function of the momentum function during test T2. Overall the flow conditions in January 2011 showed large fluctuations in specific momentum M between 0.2 to $0.5 \mathrm{~m}^{2}$. The present observations are summarised in Figure 8 together with error bars indicating the instantaneous data range. They are compared with data for safe evacuation based upon full-scale tests under carefully-controlled conditions (Fig. 8). These tests were performed mostly in laboratory, with constant water velocity. The comparison between present observations, that the authors deemed unsafe for evacuation, and past full-scale test results (Fig. 8) indicates that the latters were inappropriate. Simply any criterion solely based upon the flow velocity, water depth or specific momentum cannot account for the hazards caused by the velocity and water depth fluctuations, and flow turbulence. In the present study, large and rapid fluctuations in velocity were observed, giving median acceleration amplitude and jerk amplitude of $0.46 \mathrm{~m} . \mathrm{s}^{-2}$ and $19 \mathrm{~m} . \mathrm{s}^{-3}$ 


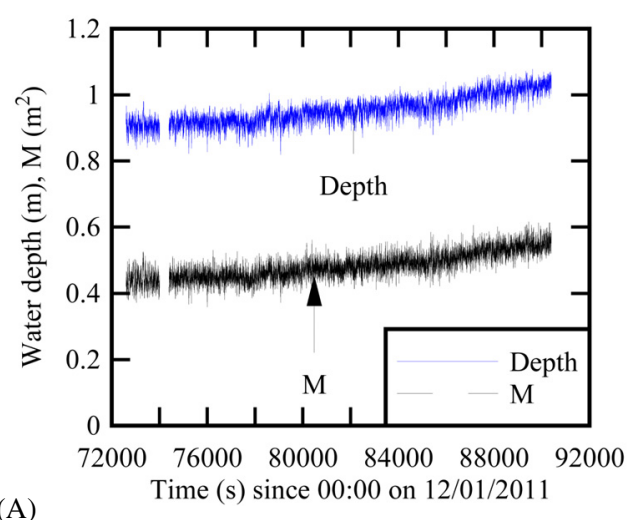

(A)

Median $=0.481 \mathrm{~m}^{2}, \mathrm{Std}=0.036 \mathrm{~m}^{2}$, Skewness $=0.353$

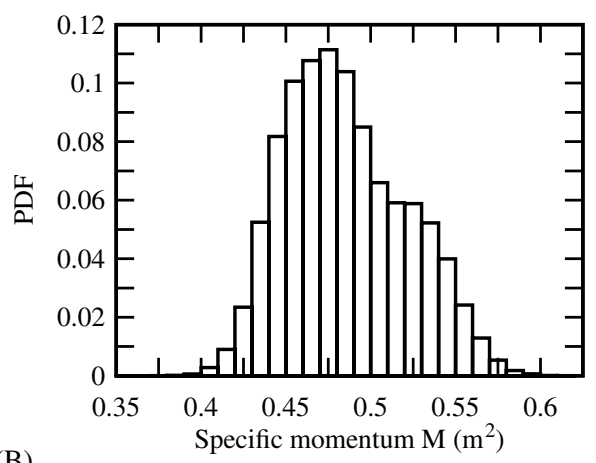

(B)

Fig. 7. Instantaneous specific momentum $\mathrm{M}$ in Gardens Point Road on 12-13 January 2011 (tests T1 and T2, location A) - (A) Time variations of instantaneous water depth and specific momentum at location A during tests T1 and T2 - (B) Normalised probability distribution function of instantaneous specific momentum at location A during test T2.

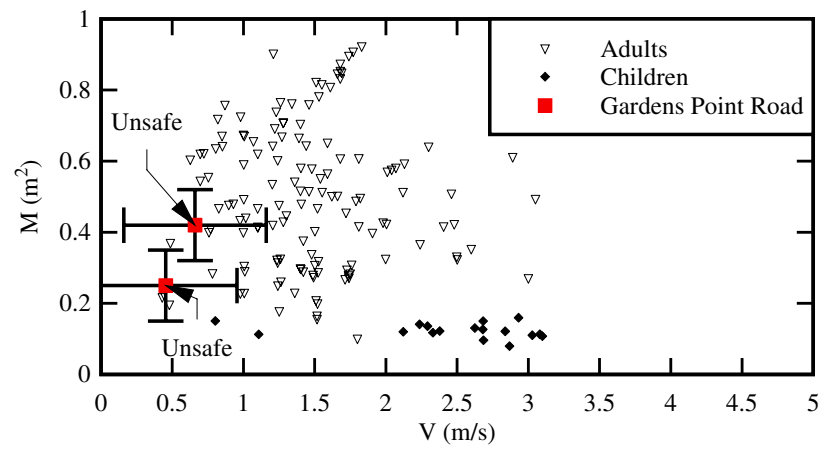

Fig. 8. Relationship between specific momentum and flow velocity: full-scale tests under carefully-controlled conditions $[4-6,10,11]$ for safe evacuation of individuals walking in floodwaters, and present observations deemed unsafe for evacuation - Error bars details instantaneous data range.

respectively, on average over the whole study. These considerations ignore further the risks associated with large debris entrained by the flow motion.

\section{Conclusion}

During the 12-13 January 2011 flood of the Brisbane River, some detailed turbulence measurements were conducted in an inundated urban setting. The turbulent velocity data were collected at relatively high frequency $(50 \mathrm{~Hz})$ continuously for several hours in Gardens Point Road. The data showed large fluctuations in all three velocity components, in the form of slow fluctuations that were linked with local topographic effects. The results were discussed with a focus on the sediment deposition during the flood recession and the safety of individuals in floodwaters. When the floodwater receded, the inundated road became disconnected from the main river channel. The flow motion was very weak, but all three velocity components presented comparatively large fluctuations with turbulence intensity $V^{\prime} /|V|$ of about $500 \%$ to $700 \%$. The suspended sediment concentration (SSC) was large, about $28 \mathrm{~kg} \cdot \mathrm{m}^{-3}$ on average, but the probability distribution of SSC showed an unusual bimodal distribution.

The force of the floodwaters was felt in Gardens Point Road, and the conditions were deemed unsafe for evacuation in floodwaters. The authors believed that the flow conditions were treacherous because of the intense turbulent mixing and the water surges which were felt at irregular intervals. A comparison with past full-scale test results suggested that many recommendations based upon the previous data sets could be hazardous and unsafe, because they did not take into account the effects of flow turbulence.

\section{References}

[1] P.D. Bates, M.S. Horritt, G. Aronica, K. Beve, Bayesian Updating of Flood Inundation Likelihoods Conditioned on Flood Extent Data. Hydrological Processes 18 (2004) $3347-3370$

[2] M. Velickovic, S. Soares-Frazao, Y. Zech, Porosity Model of Flow through an Idealised Urban District. Influence of City Alignment and of Transient Flow Character. Proc. 34th IAHR World Congress, Brisbane, Australia, 26 June-1 July, Engineers Australia Publication, Eric Valentine, Colin Apelt, James Ball, Hubert Chanson, Ron Cox, Rob Ettema, George Kuczera, Martin Lambert, Bruce Melville, Jane Sargison (eds.), (2011) 3823-3830

[3] A.H. Thieken, M. Muller, H. Kreibich, B. Merz, Flood Damage and Influencing Factors: New Insights from the August 2002 Flood in Germany, Water Res. Res. AGU 41 (2005) W12430 (DOI: 10.1029/2005WR004177)

[4] S.R. Abt, R.J. Wittier, A. Taylor, D.J. Love, Human Stability in a High Flood Hazard Zone, Water Resources Bulletin, AWRA 25 (1999) 881-890

[5] Y. Asai, T. Ishigaki, Y. Baba, K. Toda, Safety Analysis of Evacuation Routes Considering Elderly Persons during Underground Flooding, Jl of Hydroscience and Hydraulic Eng. JSCE 28 (2010) 15-21

[6] R.J. Cox, M. Yee, J.E. Ball, Safety of People in Flooded Streets and Floodways. Proceedings 8th National Conference on Hydraulics in Water Engineering, IEAust., Gold Coast, Australia, H. Chanson, J. Macintosh (eds.), 8 (2004) (CD-ROM) 
[7] H. Chanson, The 2010-2011 Floods in Queensland (Australia): Observations, First Comments and Personal Experience, Journal La Houille Blanche 1 (2011) 5-11

[8] R. Brown, H. Chanson, Turbulence and Suspended Sediment Measurements in an Urban Environment during the Brisbane River Flood of January 2011, J. Hydraulic Eng. ASCE 139 (2013) 244-252

[9] R. Brown, H. Chanson, Suspended Sediment Properties and Suspended Sediment Flux Estimates in an Urban Environment during a Major Flood Event, Water Resources Research, AGU 48 (2012) W11523 (DOI:10. 1029/2012WR012381)
[10] S. Takahashi, K. Endoh, Z-I. Muro, Experimental Study on People's Safety against Overtopping Waves on Breakwaters, Report on the Port and Harbour Institute 34 (1992) 4-31 (in Japanese)

[11] S.N. Jonkman, E. Penning-Rowsell, Human Instability in Flood Flows, Jl of the American Water Resour. Assoc. 44 (2008) 1208-1218

[12] R.A. Karvonen, A. Hepojoki, H.K. Huhta, Louhio, A. (2000), The Use of Physical Models in Dam-Break Flood Analysis. RESCDAM, Final Report of Helsinki University of Technology, Finland, 56 pages 